\title{
Editorial
}

\section{The Challenges of Studying Vertebrates in Habitat Treatment Plots}

Managers need information about effects of environmental change on populations of species. Such data often come from experiments where habitat components are manipulated and subsequent changes in population size, productivity, or behavior are measured. Research biologists, however, are often reluctant, or unable, to publish data about responses of uncommon organisms because small sample sizes reduce strength of inference as statistical power declines. These challenges to inference are real, but should not completely eliminate access to data that could be valuable to managers [1]. In general, many managers would say some data is better than no data at all. They would prefer to have some data that could be added to their own personal knowledge of a system than to have no data at all. Multiple factors influence habitat management decisions, so managers are typically keen to acquire all data they can before making decisions, even if those data are sparse.

An example of this situation comes from attempts to study responses of terrestrial vertebrates to habitat manipulation experiments designed to study plants. Such experiments are often quite expensive so many are designed to incorporate just enough area and replication to identify responses of plants, but are typically too small to ensure that sample sizes of wideranging mammals, birds, reptiles, and amphibians are large enough to allow population or demographic responses to be measured with confidence. Analytical methods that estimate habitat-associated changes in population size, reproductive success, or survival are often quite data hungry. When samples are small, confidence intervals around estimated parameters are inevitably quite large, leading to a reduction in power to detect treatment effects.

The best solution for this conundrum would be to enlarge the size of study plots so that enough individuals of species of management concern can be studied within each plot. Unfortunately, two major issues retard efforts here, too. First, for species that do respond numerically to habitat treatments, their abundances vary across study plots, but the differences in numbers across plots can still be too small to detect statistically significant effects, even when numbers change several-fold. So, even when it is clear that numbers drop substantially or a species disappears from a treatment completely, if abundances are low or variable through time in another treatment, the effect may not create statistically significant results. Second, the sizes of plots required to include a typical minimum number of 30 to 40 individuals per species that is often considered necessary for sufficiently powerful parametric statistical approaches, can be impossibly large from a logistical standpoint. This is particularly an issue when studying naturally rare species (often the species of most management interest) and studying ecosystems with relatively low productivity and therefore, lower abundances of most species. Robinson and Rompré [2], for example, estimated from studies of 10 to 12-ha plots in longleaf pine forest, a habitat supporting comparatively low numbers of birds overall [3], that a minimum plot size of 100 ha would have been required to conduct strong statistical comparisons of nest survival for just the most common species. The entire study of that longleaf community included 150 ha distributed across 15 plots, so enlarging plots by an order of magnitude would have also enlarged costs of setting up, manipulating, and maintaining the plots by at least that same amount. Thus, the costs of small plot size are both statistical and economic.

This special issue includes studies that attempt to find ways around those costs. The results include investigations of bird and herpetofaunal responses to habitat manipulations in the United States. The efforts were part of a national study of effects of fire and alternative habitat management techniques, called fire surrogates, on many aspects of biodiversity [4]. The fire and firesurrogate study is a network of sites distributed across forested ecosystems in the United States that were historically exposed to natural fires. Without fire, most of these ecosystems change dramatically over the course of a few years or decades. Species dependent on the changes to habitat structure and composition caused by fire may decline and disappear quite quickly in the absence of fire. But natural fires are quickly suppressed today, except in a very few special situations. With increasing human population size comes increased proximity of private property and travel corridors to natural areas. Therefore, the consequences of escaped fires and of smoke causing health and travel hazards has forced managers to find alternative methods to create habitat management effects similar to those caused by fire [4].

The goal of the National Fire and Fire Surrogate Study was to evaluate how alternative habitat management techniques, such as thinning, herbicide application, and combinations of those along with prescribed burns, compared with effects of fire treatments alone. Studies encompassed multiple forms of biodiversity, including understory vegetation, trees, insects, and vertebrates, as well as soils. Most sites created 10 to 12-ha study plots within relatively uniform habitat, randomly designated some plots to be left unmanipulated, and then implemented one or more of the above-mentioned treatments to the remaining plots. In most cases, all plots were studied prior to any manipulations, so before-after comparisons could be made as well. Despite the excellent design of such challenging landscape-level experiments, learning how vertebrates responded to treatments was hindered, but not completely halted, by the challenges of small plot sizes even though, by standards of many plant studies, 10 to 12 ha is quite large.

Authors of this special issue found several ways to contribute knowledge of responses to the treatments at their sites. One way forward was to focus on behavior instead of population sizes or reproductive success. Pierson et al. [5] learned that large diameter trees are important foraging sites for bark-gleaning chickadees and nuthatches and excavating woodpeckers regardless 
of treatments, and that some species preferentially selected sites that were thinned and burned, probably because of the availability of newly dead trees. They did have the good fortune of working in substantially larger plots, too. Steen et al. [6] were concerned that some amphibians and reptiles were ranging outside of 12-ha plots in longleaf pine forests, so they estimated differences in species richness across plots. By using modern estimators, they determined that species considered to be habitat generalists showed little response to treatments, but species more tightly associated specifically with longleaf pine forests were more numerous in treated than untreated plots. Such approaches utilize every observation or capture, even of the rarest species, and therefore appear to be quite useful for understanding how a community-level phenomenon such as species richness is affected by habitat treatments.

Several studies of avian nest survival are included in this issue, including a continent-wide analysis and three site-specific studies. Sample size issues were most challenging with the continent-wide analysis [7]. When attempting such comparisons, one has few species that are shared across all study sites so the temptation is to compare closely related species or members of the same guild so that sample sizes can be boosted. Yet, such comparisons are quite problematic because different species build nests in different locations and location affects risk of predation [8]. The more distantly related species are, in general, the less confidence we have in results of comparisons that group species together. For the few comparisons Farris et al. [7] were able to conduct, it appeared that no major treatment effects emerged and that the level of habitat heterogeneity in areas around plots might be more important than the treatments themselves on nest survival.

The three studies of songbird nest survival all faced challenges of small sample sizes. Interestingly, even when nest survival was quite high, as in the South Carolina study site [9], sample sizes were low because few nesting attempts were made by the individuals breeding in those plots. In plots of longleaf pine in southern Alabama, the overall population densities of songbirds were so low that it was nearly impossible to find large samples of nests, even for the most common species and even when predation rates were high, leading to multiple re-nesting attempts [2]. The strategy of those studies was to present their findings, including the raw data on nest exposure days, so that data are available for future meta-analyses. This type of contribution needs to be encouraged more often. Open access journals such as The Open Environmental Sciences Journal are the perfect outlet for these data because they are readily found with a simple web search and available to any manager or researcher without requiring an expensive journal subscription or access to a university library.

So how can studies of vertebrate responses to fire and fire surrogate treatments, or habitat treatments more generally, move forward in the future? Should we just abandon hope because it is too expensive to create plots large enough to study both plants and animals in statistically robust manners? Although it is probably best to always attempt approaches at enlarging sample sizes, some options are apparent. First, regarding nest survival, traditional methods, such as Mayfield's index [10], are very sensitive to sample sizes, but newer modeling methods appear to be somewhat less sensitive and can be informative in some situations [11]. More generally, what we wish to know is how treatments influence risk of nest failure via predation. Therefore, another way forward would be to create predictive models of nest predation risk based on information about how predators respond to habitat treatments. Using cameras on nests to identify the important predators, then tracking the spatial patterns of habitat use by following those predators around could allow us to build maps of predation risk without having to find a large number of nests $[12,13]$. This is a particularly promising approach for rare species for which we essentially have no hope of ever finding many nests.

Another way forward could be to take advantage of alternative statistical approaches. Resampling methods, for example, have rarely, if ever, been used for these kinds of studies but could provide new insights [14]. At a minimum, a bit of patience and determination to repeat studies at multiple sites and across multiple time periods so that data can build over time and be available for meta-analyses is a reasonable approach.

Plot size does matter when studying vertebrates [15]. However, contributions to our knowledge of how vertebrates respond to habitat treatments can move forward, even when small plot size creates challenges.

\section{ACKNOWLEDGEMENTS}

This is contribution 212 of the National Fire and Fire-Surrogate Study. I thank Ken Outcalt for editorial assistance and the contributing authors to this special issue for their hard work and diligence in revising their manuscripts after peer review. I also appreciate the help of twelve reviewers for very constructive feedback that greatly improved the content of the papers.

\section{REFERENCES}

[1] Berry J, Brewer GD, Gordon JC, Patton DR. Closing the gap between ecosystem management and ecosystem research. Policy Sci 1998; $31: 55-80$.

[2] Robinson WD, Rompré GR. Nest survival of understory birds in longleaf pine forests exposed to fire and fire-surrogate treatments. Open Environ Sci J 2010; 4: 71-7.

[3] Engstrom RT, Crawford RL, Baker WW. Breeding bird populations in relation to changing forest structure following fire exclusion: a fifteen-year study. Wilson Bull 1984; 96: 437-50.

[4] Schwilk D, Keeley JE, Knapp EE, et al. The national Fire and Fire Surrogate study: effects of fuel reduction methods on forest vegetation structure and fuels. Ecol Appl 2009; 19: 285-304.

[5] Pierson JC, Mills LS, Christian DP. Foraging patterns of cavity-nesting birds in fire-suppressed and prescribe-burned ponderosa pine forests in Montana. Open Environ Sci J 2010; 4: 49-60.

[6] Steen DA, Rall McGee AE, Hermann SM, Stiles JA, Stiles SH, Guyer C. Effects of forest management on amphibians and reptiles: generalist species obscure trends among native forest associates. Open Environ Sci J 2010; 4: 32-8.

[7] Farris KL, Converse SJ, Zack S, et al. Short-term effects of fire and fire-surrogate treatments on avian nest survival: a national-scale analysis. Open Environ Sci J 2010; 4: 61-70.

[8] Martin TE. Fitness costs of resource overlap among coexisting species. Nature 1996; 380: 338-40. 
[9] Kilpatrick E, Lanham JD, Waldrop TA. Effects of fuel reduction treatment on avian nest density in the Upper Piedmont of South Carolina. Open Environ Sci J 2010; 4: 78-83.

[10] Mayfield HF. Suggestions for calculating nest success. Wilson Bull 1975; 87: 456-66.

[11] Streby HM, Miles DB. Assessing ecosystem restoration alternatives in eastern deciduous hardwood forests using avian nest survival. Open Environ Sci J 2010; 4: 39-48.

[12] Klug PE, Jackrel SL, With KA. Linking snake habitat use to nest predation risk in grassland birds: the dangers of shrub cover. Oecologia 2010; 162: 803-13.

[13] Weatherhead PJ, Carfagno GLF, Sperry JH, Brawn JD, Robinson SK. Linking snake behavior to nest predation in a Midwestern bird community. Ecol Appl 2010; 20: 234-41.

[14] Simon, JL. Resampling: the new statistics. Resampling Stats, Inc. Arlington, Virginia: USA, 1997.

[15] Engstrom RT, James FC. Plot size as a factor in winter bird-population studies. Condor 1981; 83: 35-41.

W. Douglas Robinson
(Guest Editor)
Oak Creek Lab of Biology
Department of Fisheries and Wildlife
Oregon State University
Corvallis
Oregon 97331
USA
ail: douglas.robinson@oregonstate.edu

(C) W. Douglas Robinson; Licensee Bentham Open.

This is an open access article licensed under the terms of the Creative Commons Attribution Non-Commercial License (http://creativecommons.org/licenses/ by-nc/3.0/) which permits unrestricted, non-commercial use, distribution and reproduction in any medium, provided the work is properly cited. 